\title{
Geometric Effects of Sustainable Auxetic Structures Integrating the Particle Swarm Optimization and Finite Element Method
}

\author{
Sergio Luiz Moni Ribeiro Filho, Thais A. A. Silva, Luciano Machado Gomes Vieira, \\ Túlio Hallak Panzera ${ }^{\text {a*, Katarzyna Boba }}{ }^{\text {b }}$ Fabrizio Scarpa ${ }^{\mathrm{b}}$ \\ ${ }^{\mathrm{a}}$ Department of Mechanical Engineering, Centre of Innovation and Technology of Composites, \\ Federal University of São João del Rei - UFSJ, Praça Frei Orlando, 170, Centro, \\ CEP 36307-352, São João Del Rei, MG, Brazil \\ ${ }^{\mathrm{b}}$ Advanced Composites Centre for Innovation and Science, University of Bristol, UK
}

Received: October 22, 2013; Revised: January 28, 2014

\begin{abstract}
The development of new materials based on industrial wastes has been the focus of much research for a sustainable world. The growing demand for tyres has been every year exacerbating environmental problems due to indiscriminate disposal in the nature, making a potentially harmful waste to public health. The incorporation of rubber particles from scrap tyres into polymeric composites has achieved high toughness and moderate mechanical properties. This work investigates the geometric effects (thickness, width and internal cell angle) of auxetic structures made of recycled rubber composites based on experimental and numerical data. The response surface models integrated with the swarm intelligence and finite element analysis were proposed in order to obtain a range of solutions that provides useful information to the user during the selection of geometric parameters for reentrant cells. The results revealed the cell thickness ranges from $39-40 \mathrm{~mm}$ and $5.98-6 \mathrm{~mm}$, and the cell angle range from -0.01 to $-0.06^{\circ}$ maximize the ultimate strength. The same parameters were able to optimize the modulus of elasticity of rubber auxetic structures, excepting for the angle factor which must be set between $-30^{\circ}$ and $27.7^{\circ}$. The optimal Poisson's ratio was found when the cell angle ranged from $-30^{\circ}$ to $-28.5^{\circ}$, cell width ranged from $5-5.6 \mathrm{~mm}$ and $2 \mathrm{~mm}$ in thickness.
\end{abstract}

Keywords: A. Smart materials, B. Mechanical properties, C. Statistical properties/methods, D. Mechanical testing, E. Forming

\section{Introduction}

The continued interest of new cellular structures allowed the advancing and the emergence of unusual cellular solids namely as "metamaterials". A metamaterial is an artificially produced material, which is endowed with properties that do not exist in the nature. Among these materials, the reentrant honeycomb structures are highlighted, exhibiting a negative Poisson's ratio. This metamaterial, known as "Auxetic" has been investigated for various applications, for example, bulletproof vests, whose principle is based on the ability of the material to be compressed as the projectile progresses, and thus preventing penetration ${ }^{1,2}$.

Auxetic materials have a great potential in biomedical, automotive and defense applications. In 1944, Love described a material with negative Poisson's ratio. The next document reporting the evidence of an auxetic material was found 38 years later by Gibson ${ }^{3}$. In 1987, Lakes made the first discovery about the negative effect of Poisson's ratio designing a polyurethane foam (PU) with reentrant structures, which was named by anti-rubber, auxetic or dilational ${ }^{4}$. In recent years, the studies related to auxetic structures were mainly focused on the estimation of effective properties as a function of geometric dimensions ${ }^{5}$, density

*e-mail: panzera@ufsj.edu.br variations $^{6}$, electromagnetic ${ }^{7}$, acoustic and mechanical properties ${ }^{8,9}$, and the ability to absorb vibrations ${ }^{10}$.

The existence of a material having a negative Poisson's ratio means achieving non-conventional mechanical behaviour, i.e. when the structure is subjected to tensile stresses, rather than reducing its cross section with increasing deformation, it expands radially and, consequently, undergoes reduction of its cross section under compressive stresses ${ }^{9}$. Furthermore, auxetic structures have a higher resistance to indentation ${ }^{11}$ and improved acoustic properties $^{12}$. According to the theory of elasticity, the shear modulus of auxetic structures could become even larger than the bulk modulus, making these structures suitable for many applications ${ }^{6,13}$, especially in aircraft and aerospace industry.

A reentrant honeycomb configuration made from a novel solid composite based on recycled material is an innovative and sustainable solution for engineering applications. The growing demand for tyres has been every year exacerbating environmental problems due to indiscriminate disposal in the nature, making a potentially harmful waste to public health ${ }^{14}$. On a global scale, between 700 million to 1 billion new tyres are manufactured each year and this figure is expected to rise due to increasing world population, vehicle ownership and usage. Statistics show that in Brazil around 
300,000 tonnes of scrap tyres are generated per year, of which only $10 \%$ are recycled. In the United States, with a population approximately $30 \%$ higher than Brazil, the amount of rubber waste is ten times greater, of which only $5 \%$ are recycled. Currently, more than 300 million scrap tyres are stored in the USA ${ }^{15,16}$. In the United Kingdom, approximately 46 million of tyres are disposed of each year, and since European Union directives have banned the disposal of used tyres (whole and shredded) in landfills, this has created an urgent need to identify routes for reuse or for recycling the component materials for new purposes ${ }^{17}$.

The reuse of rubber wastes as dispersive phase into composite materials has been the focus of several researches ${ }^{18-21}$ exhibiting excellent flexibility, ductility and energy absorption compared with conventional materials. Besides the environmental issues, elastomers offer singular properties such as, low density, electrical insulation, high chemical resistance, high toughness and vibration absorption, making them a potential promise phase for polymeric auxetic structures ${ }^{22}$.

According to the theory of cellular materials ${ }^{3,5}$, the mechanical properties of a cellular solid can be described by geometric parameters of the unit cell and the mechanical

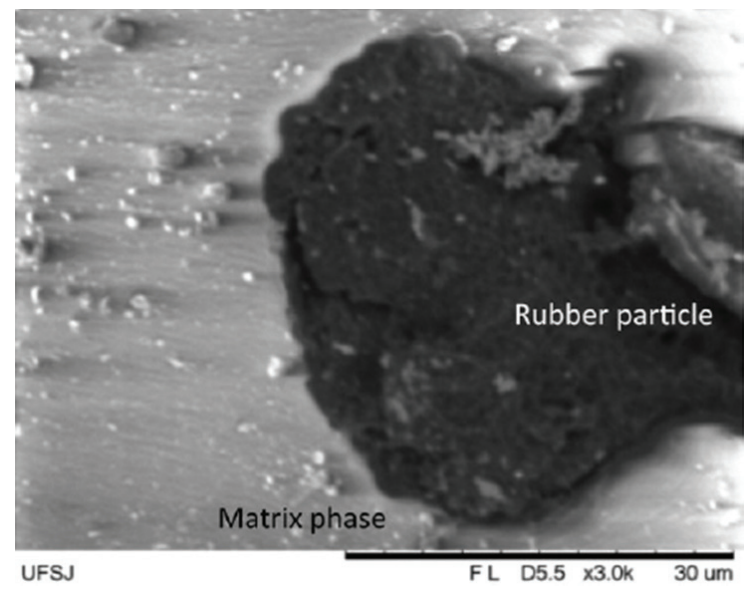

Figure 1. Backscatter-mode SEM image of rubber composite. properties of the manufactured material. Some researchers have attempted to improve composite materials with negative Poisson's ratios using different optimization methods ${ }^{23-25}$. Javadi et al. ${ }^{26}$ proposed a methodology based on the integration of finite element analysis (FEA) and evolutionary optimization algorithm (GA). Different microstructures are generated employing GA and the behaviour of each microstructure is evaluated using the FEA technique.

The addition of rubber wastes into polymeric composites appears as a viable option to moderately increase the strength, and achieve high performance in which toughness/ weight ratio is desired. In order to better understand the cell geometric parameter effects of reentrant honeycomb structures made of polymeric rubber composites, a combined methodology was proposed based on response surface analysis, finite element analysis (FEA) and swarm intelligence algorithm. The particle swarm optimization (PSO) was applied to indentify the optimal cell geometric parameters focused on the minimal Poisson's ratio and maximal ultimate strength and modulus of elasticity. The mechanical behaviour of different Poisson's negative structures made of sustainable composite was determined via experimental characterization and numerical simulation, making it possible to optimize the geometric parameters of the structure.

\section{Material and Methods}

\subsection{Composite material}

The polymeric composite was a biphasic solid constituted of an epoxy matrix phase and an elastomeric dispersive phase (rubber waste). The rubber particles were shredded, washed clean, and dried at $80^{\circ} \mathrm{C}$ for 24 hours and classified by sieving in size range of 100/200 US-Tyler (0.149/0.079 $\mathrm{mm}$ ). According to Panzera et al. ${ }^{17}$ and Silva et al. ${ }^{27}$ the composite fabricated with $25 \%$ of rubber particle size of 100/200 US-Tyler, presented improved mechanical and physical properties, which was used in the manufacture of the samples. The epoxy matrix reinforced with $25 \%$ of rubber particles showed high particle packing factor, which

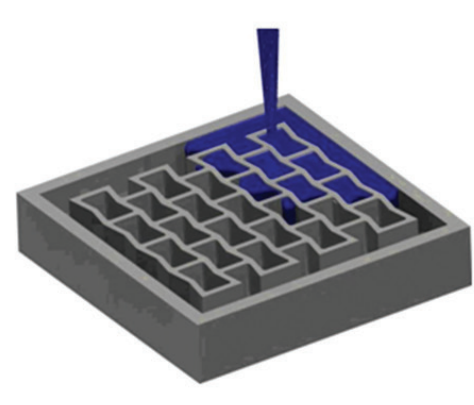

(a)

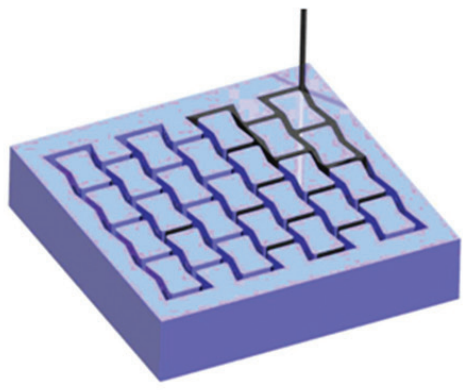

(b)

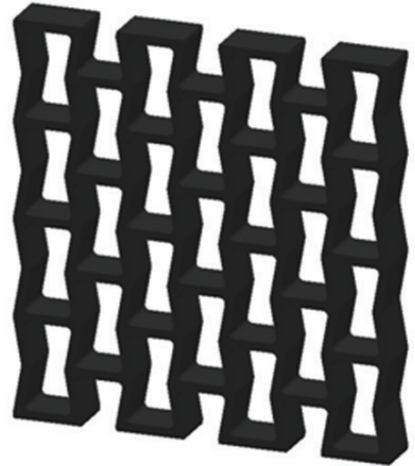

(c)

Figure 2. Model (a) mould (b) and auxetic structure (c). 
contributes to the reuse of waste rubber particles and energy absorption. Figure 1 exhibits a backscatter-mode scanning electron microscopy (SEM) image of the surface of rubber composite with 3000x of magnitude. It is observed a good adhesion between the polymeric epoxy matrix and the rubber particle due the absence of macropores in the interfacial transition zone (ITZ).

Based on CAD/CAM system, polymeric models were machined using polypropylene (Figure $2 \mathrm{a}$ ). The model was filled up with silicone to obtain the moulds with different size conditions (Figure 2b). Subsequently, the mould was filled up with the rubber composite material and removed after the curing time (Figure $2 \mathrm{c}$ ). The variables mixture time (5 min), cure time (7 days) at room temperature $\left(22^{\circ} \mathrm{C}\right)$ and the matrix phase (epoxy resin) were kept constants during the experiment. The randomization procedure was adopted during the sample fabrication and the experimental tests. This randomization let an arbitrary ordering of the experimental conditions, avoiding that non-controlled factors affect the responses.

\subsection{Tensile testing}

The elastic properties of the polymeric composite under a tensile test were conducted on an Instron testing machine (model 8810) with a load cell of $10 \mathrm{kN}$ and a non-contact extensometer. The test speed was set as $4 \mathrm{~mm} / \mathrm{min}$ for auxetic structures. The specimen was coated with a matt finish MTN94, low pressure paint, to create a stochastic black and white spot pattern as required for the digital image correlation (Figure 3a). The displacement measurements were recorded using the Digital 3D Correlation System Q-400 from Dantec Dynamics equipped with 5 mega pixel camera. In order to complete the initial part of the evaluation, markers must be set (Figure 3b), estimating coordinates of four extreme points. The distance between the points was calculated for the reference sample, providing the strain data evaluation under tensile loading. Based on the strain $\mathrm{x}-\mathrm{y}$ values, the experimental Poisson's ratio were calculated from the Equation 4: $v=-\left(\frac{\varepsilon_{\text {Transverse }}}{\varepsilon_{\text {Longitudinal }}}\right)$

Equation 4 is a general expression for the in-plane Poisson's ratio. However, centrosymmetric honeycomb configurations are special orthotropic ${ }^{3,28}$, and therefore the expression (4) has to be intended as the Poisson's ratio $\mathrm{n}_{\mathrm{yx}}$. For a special orthotropic material, the cross product $E_{x} v_{y x}=E_{y} v_{y x}$ is valid $^{3}$.

Table 1 exhibits the experimental conditions set by varying the factors (levels): internal width (10 and $20 \mathrm{~mm})$, thickness ( 2 and $4 \mathrm{~mm})$ and internal cell angle $\left(-10\right.$ to $\left.-20^{\circ}\right)$. The height and the base dimensions were set constant at 82 and 10mm, respectively (see Figure 3) for all samples. The samples were fixed in the testing machine by the use of clampers (50mm in length). The effective testing area was defined based on the longitudinal direction of two unit cells (see Figure 3).

\subsection{Modelling auxetic structures with Response Surface Method (RSM)}

The Poisson's ratio, ultimate strength $(\mathrm{MPa})$ and modulus of elasticity ( $\mathrm{GPa}$ ) were modeled using the results of finite element analysis (FEA) and experimental tests.

Table 1. Experimental conditions.

\begin{tabular}{cccc}
\hline \multirow{2}{*}{$\begin{array}{c}\text { Run } \\
\text { number }\end{array}$} & \multicolumn{3}{c}{ Factors } \\
\cline { 2 - 4 } & Width $(\mathbf{m m})$ & Thickness $(\mathbf{m m})$ & Angle $\left(^{\circ}\right)$ \\
\hline 1 & 10 & 2 & -10 \\
2 & 10 & 2 & -20 \\
3 & 10 & 4 & -10 \\
4 & 10 & 4 & -20 \\
5 & 20 & 2 & -10 \\
6 & 20 & 2 & -20 \\
7 & 20 & 4 & -10 \\
8 & 20 & 4 & -20 \\
\hline
\end{tabular}

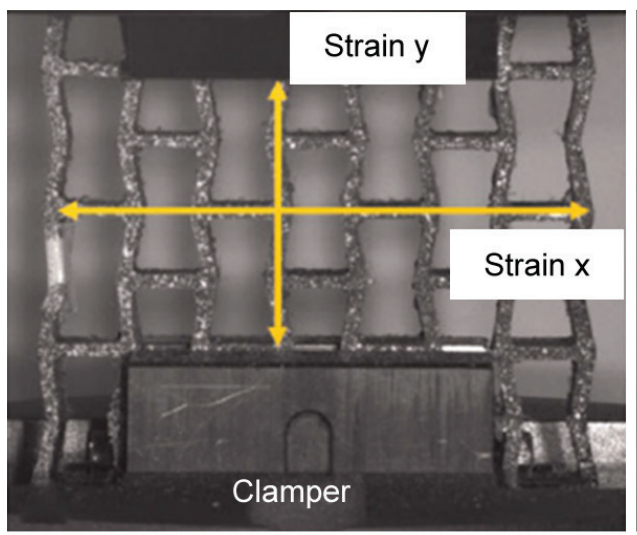

(a)

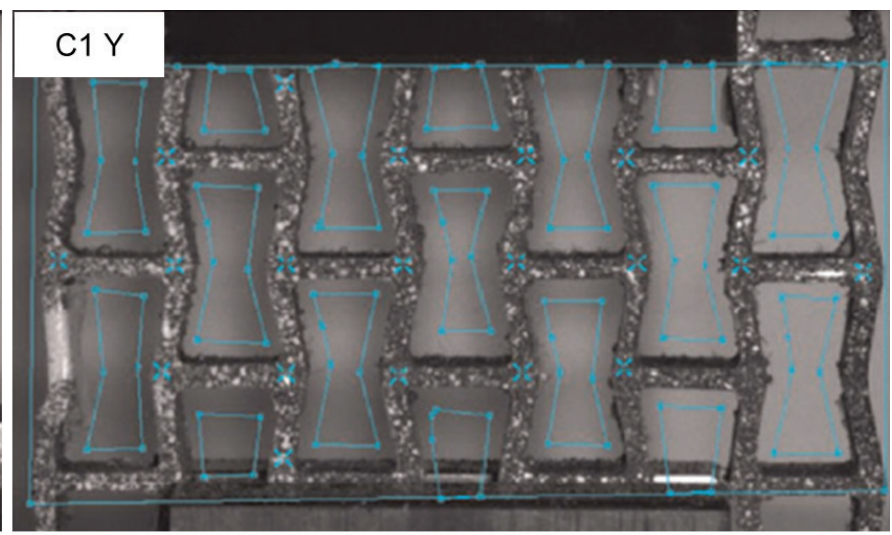

(b)

Figure 3. Tensile tests (a) and masks and marked in the area of interest for the strain analysis (b). 
Response Surface Method is an empirical methodology used for multiple regression analysis employing quantitative data. A response surface analysis is made in terms of the adjusted surface. If the surface is an adequate approximation set, then the analysis will be approximately equivalent to the analysis of the actual parameter. The response being modeled by a linear function of the independent variables, the relationship between $\mathrm{Y}$ and the predictor variables can be expressed according to a Taylor series expansion so the function approximation will be a first order model as follows:

$y=\beta_{0}+\beta_{1} X_{1}+\beta_{2} X_{2}+\ldots+\beta_{k} X_{k}+\varepsilon$

If there is curvature in the system then the approximation function is a polynomial of higher order, as the secondorder model:

$y=\beta_{0}+\sum_{i=1}^{K} \beta_{i} x_{i}+\sum_{i=1}^{K} \beta_{i i} x_{i}^{2}+\sum_{i<j}^{K} \sum \beta_{i j} x_{i} x_{j}+\varepsilon$

To estimate the coefficients $(\beta)$ in the polynomials, which are the values that minimize the sum of square errors of the model, the least square method will be applied being expressed as follows:

$\beta=\left(X^{T} X\right)^{-1} X^{T} y$

The central composite design (CCD) $\mathrm{N}=2^{\mathrm{k}}+2 \mathrm{k}+\mathrm{x}_{0}$ investigates all possible combinations of the experimental factors $(\mathrm{k})$ and the number of central points $\left(\mathrm{x}_{0}\right)$. The result $(\mathrm{N})$ corresponds to the number of the investigated experimental conditions. A polynomial quadratic equation was used to correlate each response to the independent factors based on Response Surface Method. The factors or input variables in this experiment were the cell geometric parameters such as, width, thickness and angle (Figure 4).

\subsection{Finite element analysis}

The FEA was carried to evaluate the effect of the elastic properties variation on the numerical data for central composite design. The experimental and numerical Poisson's ratio and mechanical properties values showed a good correlation, validating the adopted methodology. Thus, the finite element method was able to estimate the mechanical behaviour of reentrant structures designed with different geometric range levels, such as: internal width (30 and 40mm), thickness (6 mm), internal cell angle $(-1$ and $-30^{\circ}$ ), being able to expand the limits of experimental conditions (see Table 2).

Non-linear elastic and non-linear plastic uniaxial stresses were modeled using hexahedral elements of type C3D8R with eight nodes. The loading was applied upon the top surface of the auxetic structure, while the base of the model was constrained in the loading direction. The rubber composite material can be considered isotropic, exhibiting elastic modulus of $2.12 \mathrm{GPa}$ and Poisson ratio of 0.28 . Figure 5 shows typical undeformed (a) and deformed (b) FE meshes. The strain field of a cell was determined through the use of tensile forces ranging from $100 \mathrm{~N}$ to $10 \mathrm{kN}$. High strain levels were observed not only at the centre (see Figure 5a), but also at the top of the cell due to the transverse deformation (see Figure 5b).

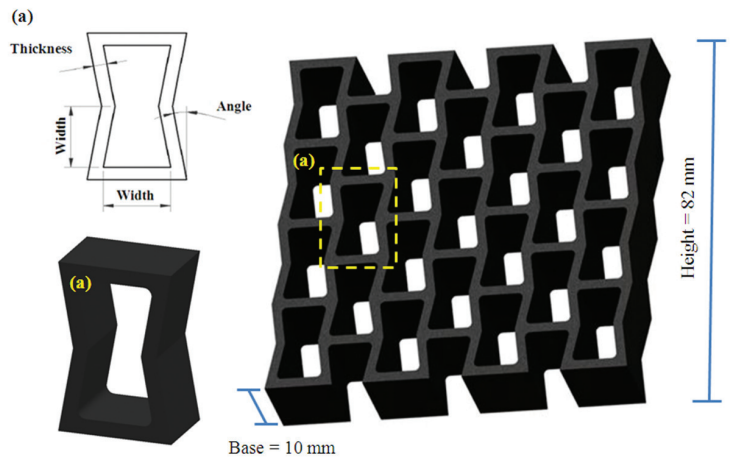

Figure 4. Re-entrant cell characteristics.

Table 2. FEM conditions.

\begin{tabular}{cccc}
\hline \multirow{2}{*}{$\begin{array}{c}\text { Run } \\
\text { number }\end{array}$} & \multicolumn{3}{c}{ Factors } \\
\cline { 2 - 4 } & Width (mm) & Thickness (mm) & Angle $\left(^{\circ}\right)$ \\
\hline 1 & 30 & 6 & -1 \\
2 & 30 & 6 & -30 \\
3 & 30 & 6 & -1 \\
4 & 30 & 6 & -30 \\
5 & 40 & 6 & -1 \\
6 & 40 & 6 & -30 \\
7 & 40 & 6 & -1 \\
8 & 40 & 6 & -30 \\
\hline
\end{tabular}

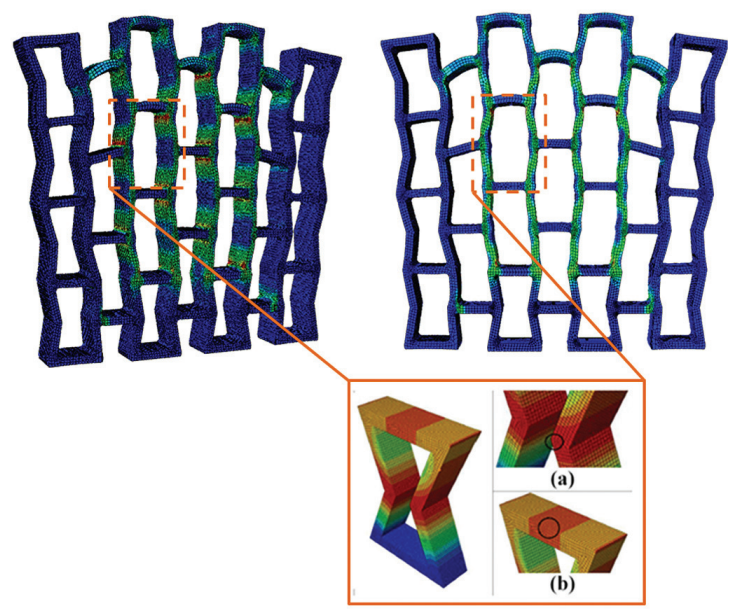

Figure 5. MEF model for explicit simulation with deformation. Strain field of auxetic cell (a) and strain concentration areas (b).

\subsection{Accuracy of the models}

The analysis of variance (ANOVA) was used to verify the adequacy of the RSM models with a confidence interval of $95 \%$. The analysis of variance (ANOVA) was carried out to evaluate whether the main and/or the interaction factors are statistically significant. Table 3 shows the ANOVA results for the models of mechanical properties in the auxetic structures. The parameter F represents the "F-ratio", calculated by dividing the mean square of each factor 
adjusted by the mean square error adjusted. The "P-value" indicates which system effects are statistically significant for the model. If the "P-value" is less than or equal to $\alpha$ it is concluded that the effect is significant. The value of $\alpha$ of 0.05 indicates the level of significance at confidence interval of $95 \%$.

The coefficient of determination " $\mathrm{R}^{2}$ adjusted" provides a variability of the observed response values and it can be explained by the controllable factors and their interactions. Larger values of " $\mathrm{R}^{2}$ adjusted" indicate greater predictive ability of the variability in the responses variables based on the width, thickness and angle factors.

The quadratic models of the response equations which are obtained for Poisson' ratio, ultimate strength and modulus of elasticity based on the factors are given below:

Poisson $=-2.2225+0.1365 *$ Width $+0.6875 *$ Thickness $+0.1235 *$ Angle $-0.0425 *$ Width*Thickness $-0.0041 *$ Width*Angle $-0.012 *$ Thickness*Angle

Ultimate strength $=2.3275-0.1195 *$ Width -1.2825 . $*$ Thickness $-0.2395 *$ Angle $+0.1255 *$ Width.*Thickness + 0.0059.*Width.*Angle + 0.053.*Thickness.*Angle

Modulus of elasticity $=945.478-43.1616 *$ Width $-291.862 *$ Thickness $+16.3523 *$ Angle $+16.8673 *$ Width $*$ Thickness $-0.694465 *$ Width*Angle $-2.72268 *$ Thickness*Angle
The $\mathrm{R}^{2}$ values for Poisson's ratio, ultimate strength and and modulus of elasticity responses were $0.9485,0.9827$, and 0.9901 , respectively, which reveals high accuracy of the models.

Mathematical models of the RSM were used to predict the responses of the reentrant structures for each variation of the following factors: width, thickness and angle. The theoretical values were compared with the experimental values for the responses. Table 4 shows the experimental and predictive values.

The average error rate for modulus of elasticity, ultimate strength and Poisson's ratio models with 8 sets of response surface method is found to be $9.11 \%, 10.90 \%$, and $19.85 \%$, respectively. Table 5 shows the percentage accuracy for auxetic models.

In order to validate the run data, the maximum error of $25.64 \%, 27.31 \%$ and $29.16 \%$ were observed. Thus, the experimental values follow the same trend of the RSM models. The percentage accuracy was calculated by Equation 8:

$$
\Delta=\left(\frac{y_{\exp }-y_{\text {theoretical }}}{y_{\exp }}\right) .100
$$

Where: $y_{\exp }$ is the experimental value and $y_{\text {theoretical }}$ is the predicted value.

Table 3. Analysis of variance for auxetic models.

\begin{tabular}{|c|c|c|c|c|c|c|}
\hline \multirow[t]{2}{*}{ ANOVA } & \multicolumn{2}{|c|}{ Poisson's ratio model } & \multicolumn{2}{|c|}{ Modulus of elasticity model } & \multicolumn{2}{|c|}{ Ultimate Strength model } \\
\hline & $\mathbf{F}$ & $\mathbf{P}$ & $\mathbf{F}$ & $\mathbf{P}$ & $\mathbf{F}$ & $\mathbf{P}$ \\
\hline Regression & 148.72 & 0.063 & 24.37 & 0.154 & 9.46 & 0.244 \\
\hline Linear & 218.89 & 0.05 & 25.15 & 0.145 & 11.48 & 0.213 \\
\hline Width & 411.51 & 0.031 & 74.25 & 0.074 & 32.63 & 0.11 \\
\hline Tickness & 176.51 & 0.048 & 0.04 & 0.879 & 1.75 & 0.412 \\
\hline Angle & 68.65 & 0.076 & 1.16 & 0.476 & 0.07 & 0.831 \\
\hline Interaction & 78.54 & 0.083 & 23.59 & 0.15 & 7.44 & 0.262 \\
\hline Width*Tickness & 176.51 & 0.048 & 66.25 & 0.078 & 18.1 & 0.147 \\
\hline Width*Angle & 39.51 & 0.1 & 2.81 & 0.343 & 1 & 0.5 \\
\hline Tickness*Angle & 19.61 & 0.141 & 1.73 & 0.414 & 3.23 & 0.323 \\
\hline $\mathrm{R}^{2}$ (adjusted) & \multicolumn{2}{|c|}{$99.22 \%$} & \multicolumn{2}{|c|}{$95.25 \%$} & \multicolumn{2}{|c|}{$98.27 \%$} \\
\hline
\end{tabular}

Table 4. Comparison of experimental and predicted values of auxetic structure.

\begin{tabular}{ccccccccc}
\hline \multirow{2}{*}{ Width } & Thickness & Angle & \multicolumn{3}{c}{ Experimental values } & \multicolumn{4}{c}{ PSO Values } \\
\cline { 3 - 9 } & & & $\begin{array}{c}\text { Modulus } \\
\text { of elasticity } \\
\text { (MPa) }\end{array}$ & $\begin{array}{c}\text { Ultimate } \\
\text { Strength } \\
\text { (MPa) }\end{array}$ & $\begin{array}{c}\text { Poisson's } \\
\text { ratio }\end{array}$ & $\begin{array}{c}\text { Modulus } \\
\text { of elasticity } \\
\text { (Mpa) }\end{array}$ & $\begin{array}{c}\text { Ultimate } \\
\text { Strength } \\
\text { (MPa) }\end{array}$ & $\begin{array}{c}\text { Poisson's } \\
\text { ratio }\end{array}$ \\
\hline 10 & 2 & -10 & 217.5 & 1.97 & -0.86 & 227.8611 & 1.8225 & -0.9175 \\
10 & 2 & -20 & 198.6 & 2.42 & -1.56 & 188.2382 & 2.5675 & -1.5025 \\
20 & 4 & -10 & 338.1 & 4.09 & -0.06 & 348.4592 & 3.9425 & -0.0775 \\
20 & 4 & -20 & 443.1 & 2.89 & -0.01 & 432.7364 & 3.0375 & -0.0125 \\
10 & 4 & -10 & 46.3 & 0.56 & -0.12 & 35.9367 & 0.7075 & -0.1525 \\
10 & 4 & -20 & 40.407 & 0.54 & -0.44 & 50.7674 & 0.3925 & -0.4975 \\
20 & 2 & -10 & 213.4 & 2.40 & 0.06 & 203.0376 & 2.5475 & 0.0075 \\
20 & 2 & -20 & 222.5 & 2.85 & -0.13 & 232.8612 & 2.7025 & -0.1675 \\
\hline
\end{tabular}


Table 5. Perceptual error for experimental and simulated values of auxetic models.

\begin{tabular}{cccccc}
\hline \multirow{2}{*}{ Width } & Thickness & Angle & \multicolumn{3}{c}{ Perceptual error } \\
\cline { 3 - 6 } & & & Modulus of elasticity (\%) & Ultimate Strength (\%) & Poisson's ratio (\%) \\
\hline 10 & 2 & -10 & -4.76372 & 7.48731 & -6.68605 \\
10 & 2 & -20 & 5.217422 & -6.09504 & 3.685897 \\
20 & 4 & -10 & -3.06395 & 3.606357 & -29.1667 \\
20 & 4 & -20 & 2.338885 & -5.10381 & 25 \\
10 & 4 & -10 & 22.38294 & -26.3393 & 27.38095 \\
10 & 4 & -20 & -25.6401 & 27.31481 & -13.0682 \\
20 & 2 & -10 & 4.855858 & -6.14583 & -25 \\
20 & 2 & -20 & -4.65672 & 5.175439 & -28.8462 \\
\hline
\end{tabular}

\subsection{Swarm intelligence}

The term swarm intelligence is employed to define algorithms motivated in the biological study of selforganized behaviors of insect colonies and animal societies. The PSO methodology was originally proposed by Kennedy and Eberhart ${ }^{29}$, and it was firstly intended for simulating social behavior ${ }^{30}$. Swarm intelligence is a population based metaheuristic search technique inspired by the social behavior of organisms such as bird flocking, fish schooling and herd animals. The basic principle of particle swarm algorithms is molded on the hypothesis that probable solutions (particles) will be flown via space with acceleration towards more optimum solutions.

The objective of optimization is to minimize the Poisson's ratio and maximize ultimate strength, ultimate strain and modulus of elasticity. The development of PSO was based on the RSM mathematic models. The initial population of the model was formed by 10000 individuals who evolved during 100 interactions. The response surface models of Poisson's ratio, ultimate strength, ultimate strain and modulus of elasticity were integrated with a particle swarm optimization to satisfy optimal process parameter. The optimization problem was formulated as follows:

- $\operatorname{Min} f$ (poisson)

- Maxf (ultimate strength)

- Maxf (ultimate strain)

- $\operatorname{Max} f(M O E)$

- Subject to

- $10(\mathrm{~mm} / \mathrm{mm}) \leq$ Width $\leq 40(\mathrm{~mm})$;

- $2(\mathrm{~mm}) \leq$ Thickness $\leq 6$ (mm);

- $-1^{\circ} \leq$ Angle $\leq-40^{\circ}$.

PSO started with a population of randomly generated solutions in an $\mathrm{n}$-dimensional space. A preliminary exploration of the design space was performed using Uniform Latin Hypercube. Furthermore, 100 particles were created and distributed in the design space according to an uniform distribution applied to each one of the input variables describing the optimization problem. The basic steps of the algorithm are summarized as follows:

$\overrightarrow{\mathrm{x}}_{\mathrm{i}}(t)=\overrightarrow{\mathrm{x}}_{\mathrm{i}}(\mathrm{t}-1)+\overrightarrow{\mathrm{v}}_{\mathrm{i}}(\mathrm{t})$

$\overrightarrow{\mathrm{v}}_{\mathrm{i}}(\mathrm{t})=\mathrm{W} \overrightarrow{\mathrm{v}}_{\mathrm{i}}(\mathrm{t}-1)+\mathrm{c}_{1} \mathrm{r}_{1}\left(\overrightarrow{\mathrm{x}}_{\text {pbest }_{\mathrm{i}}}-\overrightarrow{\mathrm{x}}_{\mathrm{i}}(\mathrm{t})\right)+\mathrm{c}_{2} \mathrm{r}_{2}\left(\overrightarrow{\mathrm{x}}_{\text {g best }}-\overrightarrow{\mathrm{x}}_{\mathrm{i}}(\mathrm{t})\right)$

where:
- $\overrightarrow{\mathrm{x}}_{\mathrm{i}}(t)$ is $\mathrm{i}$-th particle of the population at the $\mathrm{t}$-th interaction. Each particle represents a probable solution to the problem being solved;

- $\overrightarrow{\mathrm{v}}_{\mathrm{i}}(\mathrm{t})$ is the velocity vector;

- $W$ is the inertia weight that is used to control the impact of the previous history of velocities on the current velocity of a given particle;

- $\overrightarrow{\mathrm{x}}_{\text {pbest }}$ is the best candidate solution found for the i-th particle;

- $\overrightarrow{\mathrm{x}}_{\text {gbest }}$ represents the best particle among all the particles in the swarm. In other words, is the best candidate solution for the entire population;

- $r_{1}$ and $r_{2}$ are random number in the range 0 and 1 ;

The constants $c_{1}$ and $c_{2}$ represent the contributions "Cognition" and "social" that influence each particle toward pbest and gbest positions, respectively.

\section{Results and Discussion}

A Swarm intelligent algorithm was developed to simulate PSO-based optimization of auxetic structures using RSM models. The optimal Poisson's ratio obtained from PSO simulation was found when the cell geometric parameters are set as: $-30^{\circ}$ to $-28.5^{\circ}$ for angle, $2 \mathrm{~mm}$ for thickness and 5 to $5.6 \mathrm{~mm}$ for width as shown in Figure 6. Moreover, for thickness equal to $6 \mathrm{~mm}$, the parameter levels which minimize the Poisson's ratio are highlighted as follow: width $(34.5-40 \mathrm{~mm})$ and angle $\left(-10^{\circ}\right.$ to $\left.-1^{\circ}\right)$ (see Figure 7). The Poisson's ratio for the auxetic structures varied from -2.889 to 3.147 . The optimal values selected in Swarm simulation closely agree with the parametric and experimental analysis carried out by Scarpa and co-workers ${ }^{28}$ , revealing that high rib thickness tends to decrease the magnitude of the Poisson's ratio due to shear deformation of the cross section of the cell walls.

Figure 8 and 9 reveal the cell geometric parameters varying from $-0.01^{\circ}$ to $-0.06^{\circ}$ for angle, $5.985-6 \mathrm{~mm}$ for thickness and 39-40 mm for width, maximize the ultimate strength $(\mathrm{MPa})$ of the auxetic structure. The variations of optimal ultimate strength closely agree with the FEM investigations carried out by Yang et al. ${ }^{5}$. The authors reported that the larger the cell width is, the greater the values of structural Poisson's ratio are. Furthermore, a large cell width means a stiffer structure. 

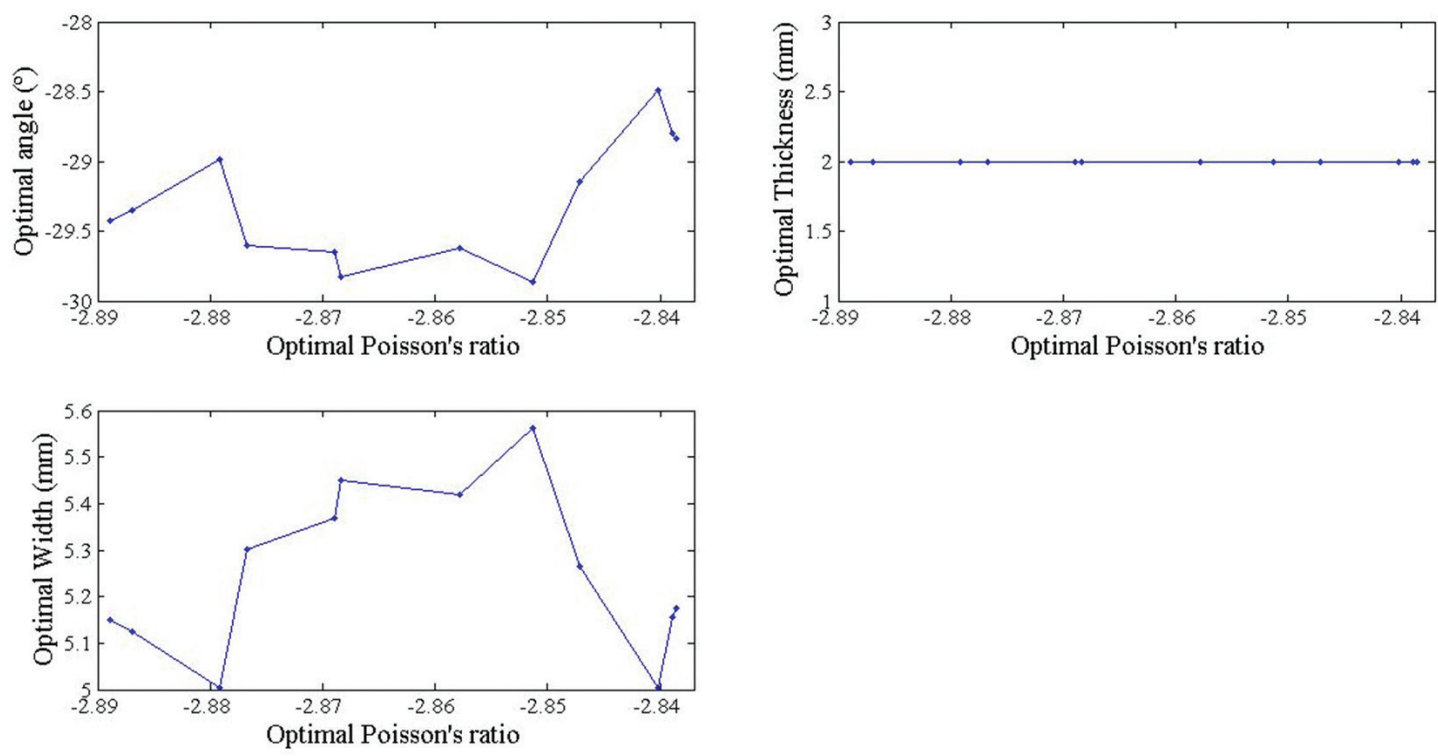

Figure 6. Optimal Poisson's ratio for angle, thickness and width.

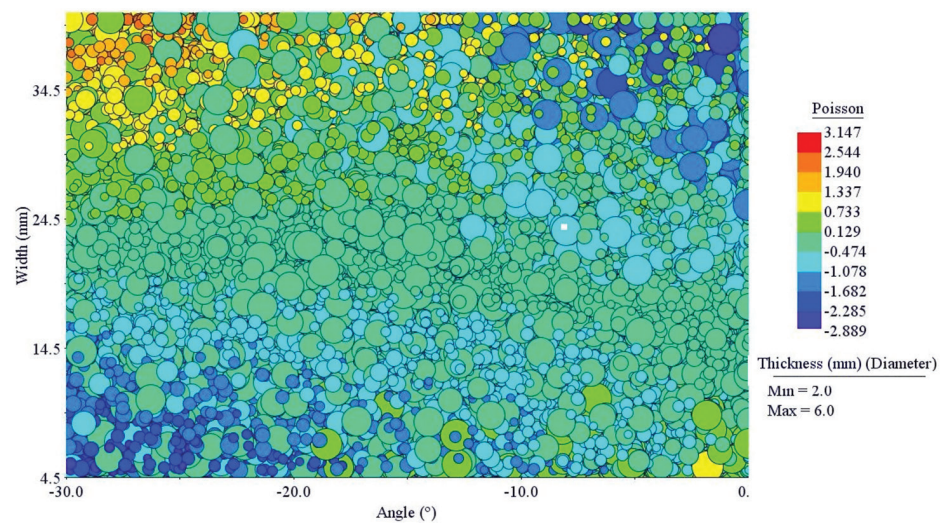

Figure 7. Relationship between width, thickness, and angle for Poisson's ratio.
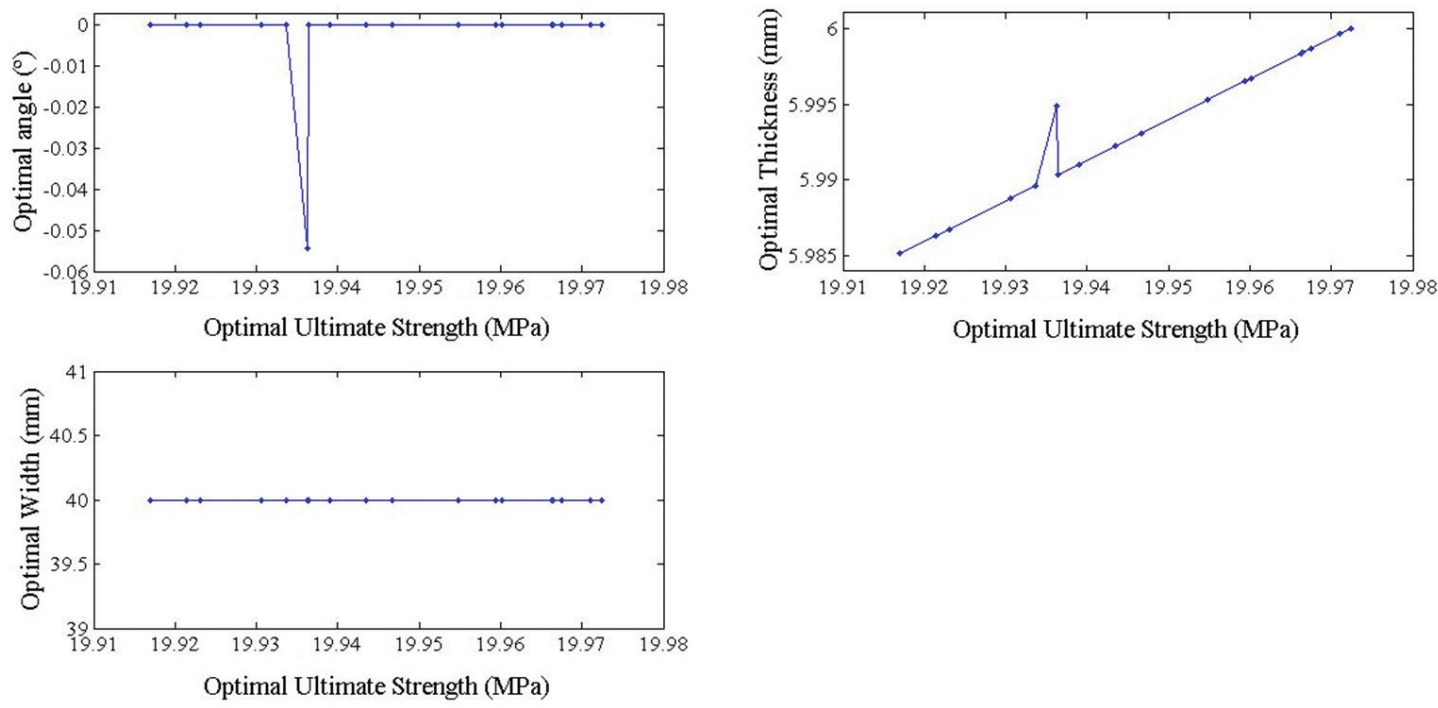

Figure 8. Optimal Ultimate strength for angle, thickness and width. 


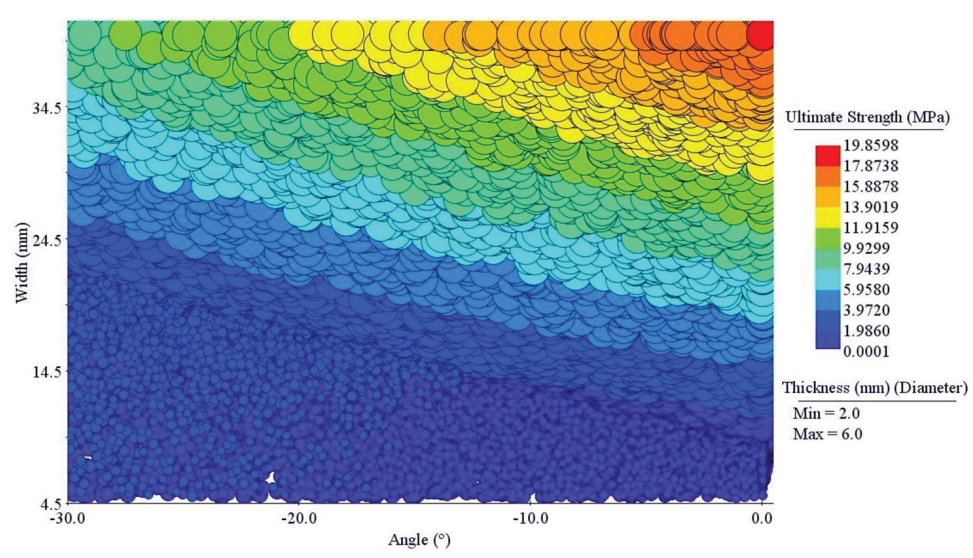

Figure 9. Relationship between width, thickness, and angle for ultimate strength (MPa).
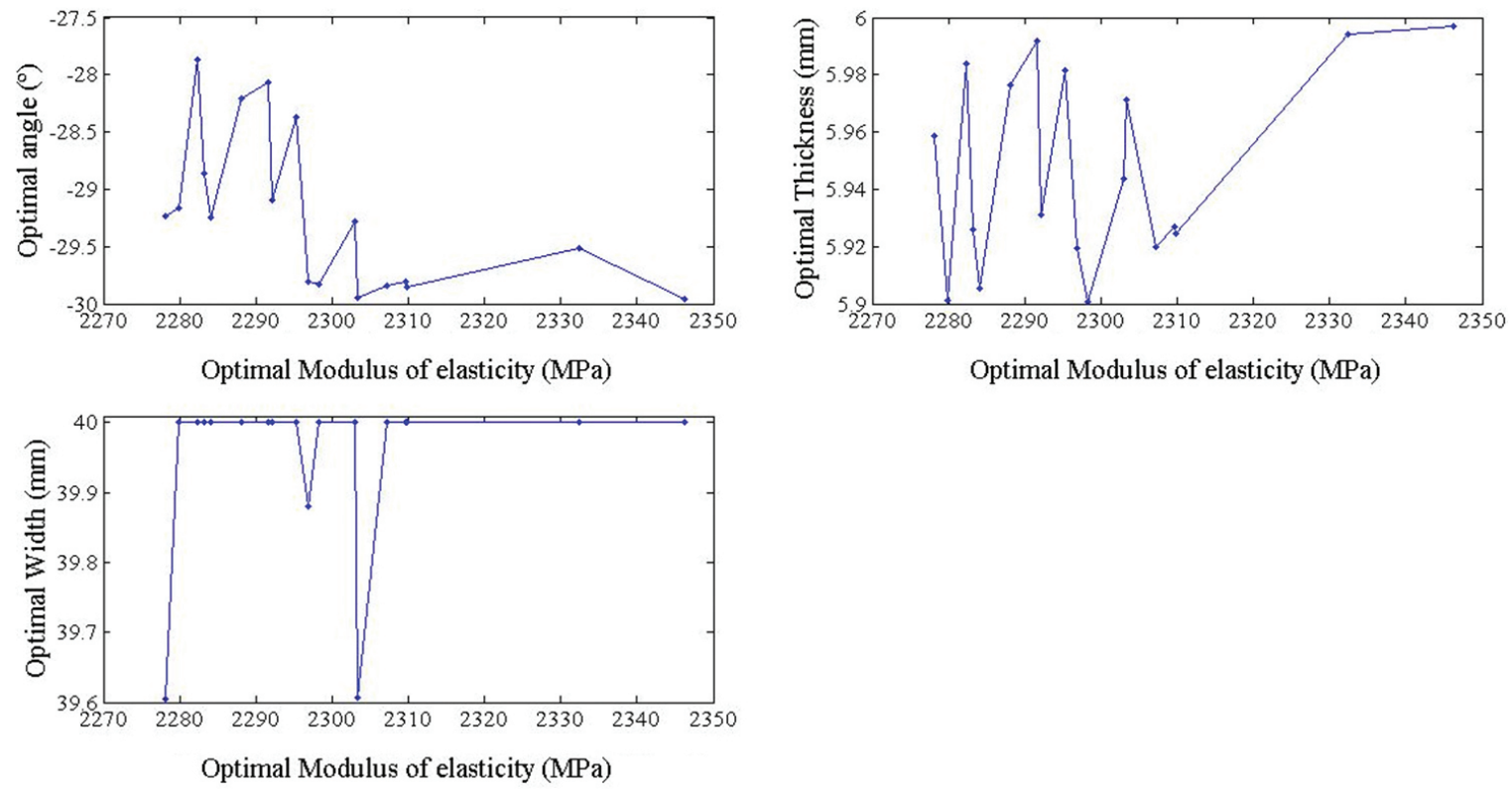

Figure 10. Optimal Modulus of elasticity for angle, thickness and width.

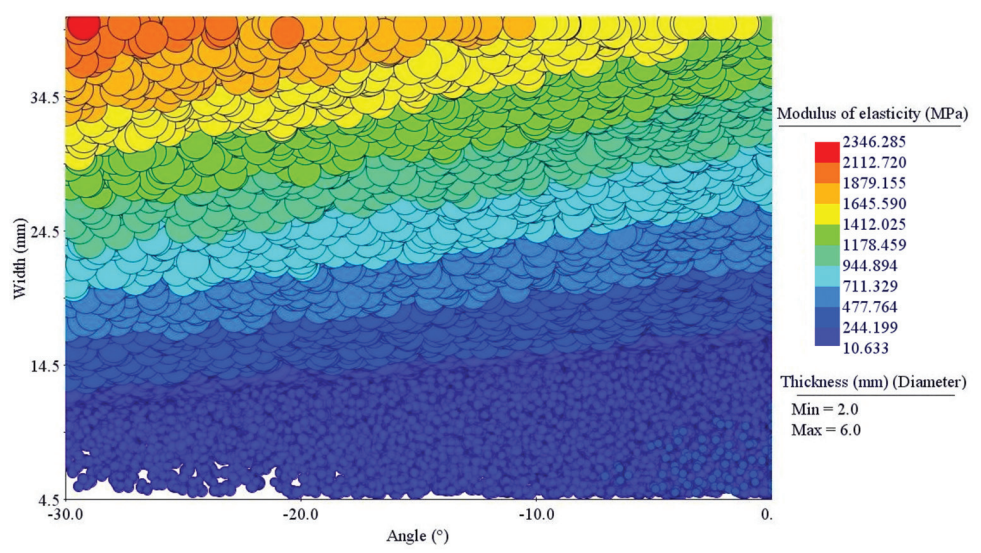

Figure 11. Relationship between width, thickness, and angle for modulus of elasticity (MPa). 

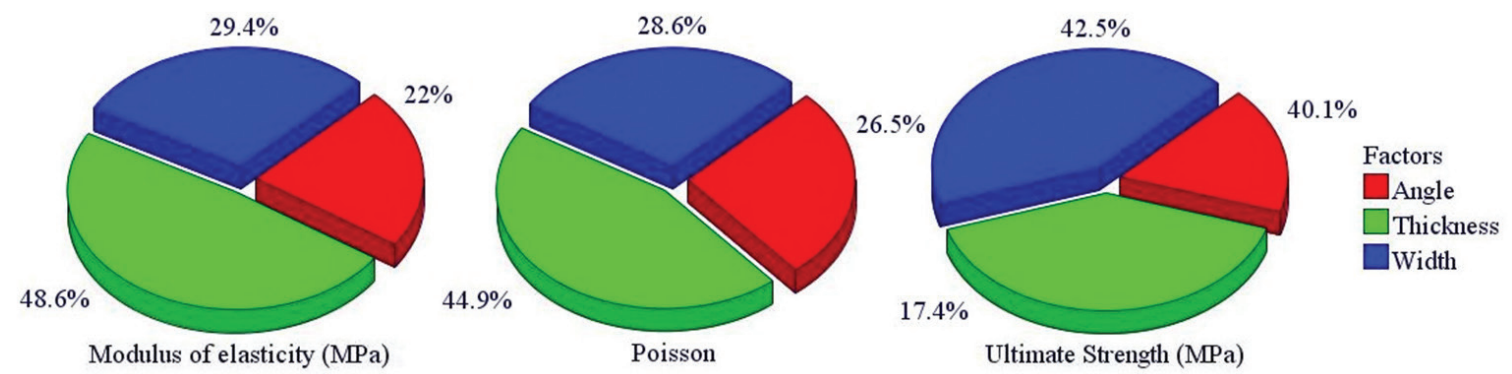

Figure 12. Sensibility analysis for MOE, Poisson's ratio and ultimate strength.
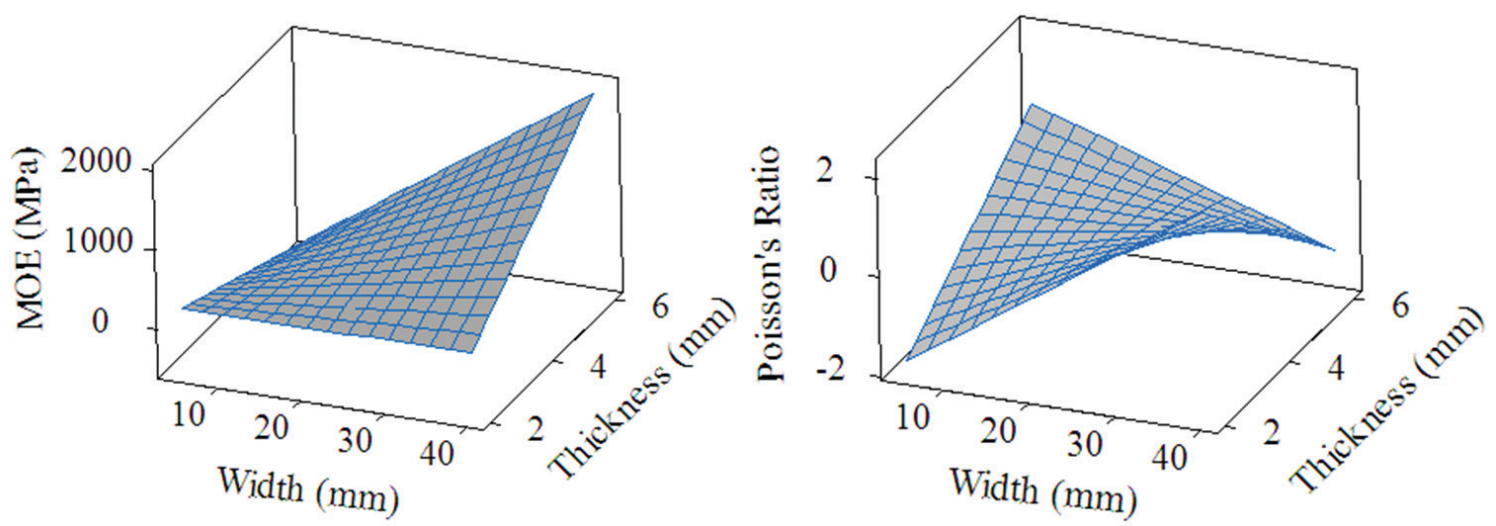

Figure 13. Interaction effects of width and Thickness on modulus of elasticity and poisson's ratio.

Figure 10 and 11 exhibit the optimum point for auxetic structures considering the modulus of elasticity (MPa). The parameter levels which optimize the modulus of elasticity are highlighted as follows: width $(39.6-40 \mathrm{~mm})$, thickness (5.9-6 mm) and angle $\left(-30^{\circ}\right.$ to $\left.-27.7^{\circ}\right)$. The modulus of elasticity for negative Poisson's ratio structures varied from 10.633 to $2346.285 \mathrm{MPa}$. Lee et al. ${ }^{31}$ investigated the effect of the cell angle on the modulus of elasticity of auxetic structures, reporting a reduction as the inverted angle of cell ribs increased. However, the swarm optimization demonstrated the modulus of elasticity increases with the decrease of cell angle on the rubber composites.

Figure 12 exhibits the sensibility analysis for the factors width (mm), thickness ( $\mathrm{mm}$ ) and angle (degree) for Poisson's ratio, ultimate strength (MPa), and young's modulus (MPa) responses. The thickness is the most significant factor affecting the Poisson's ratio and modulus of elasticity ( $44.9 \%$ and $48.6 \%$, respectively). The angle variation is an important factor affecting the ultimate strength (40.1\%). Furthermore, the width variation (42.5\%) provides large influence on the ultimate strength.

The second order RSM based models for Poisson's ratio, ultimate strength, and modulus of elasticity were employed to analyze the factor interaction effects on auxetic structures responses by plotting 3D-response surface graphs (Figure 13). The lower level of thickness $(2 \mathrm{~mm})$ and width $(10 \mathrm{~mm})$ provided higher modulus of elasticity (MPa) and lower Poisson's ratio values on the auxetic structure. The reduction of the unit cell thickness from 4 to $2 \mathrm{~mm}$ contributes not only to decrease but also to increase the overall Poisson's ratio and MOE (MPa) of the

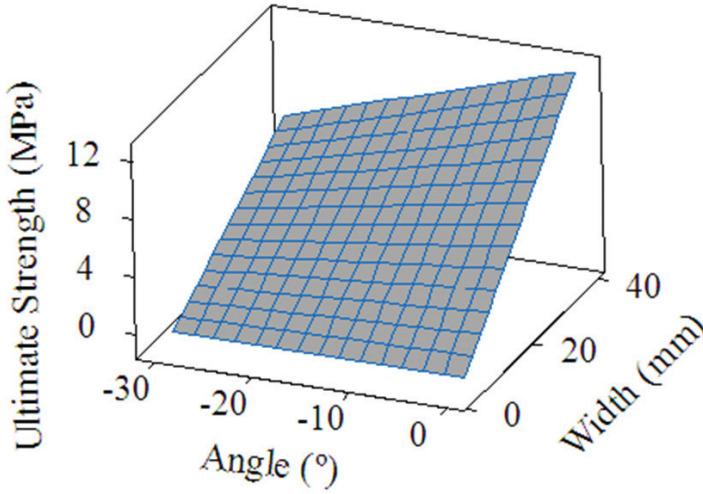

Figure 14. Interaction effects of angle and width on ultimate strength (MPa).

cellular structure mainly when the higher width $(40 \mathrm{~mm})$ is set. Lower Poisson's ratio and modulus of elasticity were achieved when the lower level of cell width was set.

Figure 14 shows the interaction surface plot of the angle and width factors for ultimate strength response. The ultimate strength is highly sensitive to thickness and angle variations, the strength rises when the width and angle are increased. The larger level of angle $\left(-1^{\circ}\right)$ and width $(40 \mathrm{~mm})$ provided the highest ultimate strength values in this analysis.

\section{Conclusion}

Swarm intelligence is an optimization technique inspired by the ability of flocks of birds, schools of fish, and herd 
animals adapt to their environment, on the others words, the evolution is based in the development of each individual. PSO has shown to be an efficient and robust optimization algorithm to evaluate auxetic structures. The experimental and numerical Poisson's ratio and mechanical properties values showed a good agreement, validating the adopted methodology. Furthermore, the interfacial zone transition (ITZ) characteristics of the composite ensure an excellent adhesion between matrix phase and the elastomeric dispersive phase (rubber waste).

The results revealed the increase of angle provides the decrease of Poisson's ratio and ultimate strength of the auxetic structures. In addition, the variation of the angle exhibited large influence on the modulus of elasticity. The swarm optimization demonstrated that the modulus of elasticity increased when the angle of cell decreased.

In general, auxetic structures exhibited different geometric parameters to optimize the responses. In order to maximize the ultimate strength, the width, thickness, and angle must be set at: $39-40 \mathrm{~mm}, 5.98-6 \mathrm{~mm}$ and -0.01

\section{References}

1. Ruzzene M. Vibration and sound radiation of sandwich beams with honeycomb truss core. In: Proceedings of the ASME Noise Control and Acoustics Division; 2003; Washington, USA. Washington: American Society of Mechanical Engineers; 2003. p. 1-14.

2. Evans KE and Alderson KL. Auxetic materials: the positive side of being negative. Engineering Science and Education Journal. 2000; 9(4):148-154.

3. Gibson LJ and Ashby MF. Cellular solids: structure and properties. 2nd ed. Cambridge: Cambridge University Press; 1997.

4. Grima JN, Attard D, Ellul B and Gatt R. An improved analytical model for the elastic constants of auxetic and conventional hexagonal honeycombs. Cellular Polymers. 2011; 30(6):287310.

5. Yang DU, Lee S and Huang FY. Geometric effects on micropolar elastic honeycomb structure with negative Poisson's ratio using the finite element method. Finite Elements in Analysis and Design. 2003; 39(3):187-205.

6. Whitty JP, Nazare MF and Alderson A. Modelling the effects of density variations on the in-plane Poisson's ratios and Young's moduli of periodic conventional and re-entrant honeycombs - Part 1: Rib thickness variations. Cellular Polymers. 2002; 21(2):p.69-98.

7. Kopyt P, Damian R, Celuch M and Ciobanu R. Dielectric properties of chiral honeycombs: modelling and experiment. Composites Science and Technology. 2000; 70:1080-1088.

8. Smith FC, Scarpa F, Burriesci G and Spieinter P. Simultaneous optimization of the electromagnetic and mechanical properties of honeycomb materials. Proceedings of SPIE. 2002; 4701:582591.

9. Scarpa F, Yates JR, Ciffo LG and Patsias S. Dynamic crushing of auxetic open-cell polyurethane foam. Proceedings of the Institution of Mechanical Engineers, Part C: Journal of Mechanical Engineering Science. 2002; 216(12):1153-1156.

10. Scarpa F, Remillat C, Landi F and Tomlinson G. Damping modelization of auxetic foams. Proceedings of SPIE. 2000; 3989:336-343. to $-0.06^{\circ}$, respectively. The same parameters was able to optimize the modulus of elasticity on rubber composite, excepting for the angle factor which must be set from $-30^{\circ}$ to $27.7^{\circ}$. The optimal Poisson's ratio obtained from PSO simulation were found when the cell geometric parameters ranged from $-30^{\circ}$ to $-28.5^{\circ}$ for angle, $5-5.6 \mathrm{~mm}$ for width, and $2 \mathrm{~mm}$ in thickness.

The width factor significantly affected the geometric responses with $29.4 \%, 28.6 \%$ and $42.5 \%$ for MOE, Poisson's ratio and ultimate strength, respectively. Moreover, the thickness variation generates great influence on the modulus of elasticity (48.6\%) and Poisson's ratio (44.9\%). Finally, the angle was the most important factor maximizing the ultimate strength $(40.1 \%)$.

\section{Acknowledgments}

The authors would like to thank the Brazilian Research Agencies, CNPq and FAPEMIG, for the financial support provided.

11. Lakes RS and Elms K. Indentability of conventional and negative Poisson's ratio foams. Journal Composite Materials. 1993; 27:1193-1202.

12. Scarpa F, Giacomin J, Zhang Y and Pastorino P. Mechanical Performance of Auxetic Polyurethane foam for antivibration glove applications. Cellular Polymers. 2005; 24:253-268.

13. Chen C, Harte AM and Fleck NA. The plastic collapse of sandwich beams with a metallic foam core. International Journal of Mechanical Sciences. 2001; 43(6):1483-1506.

14. Snyder RH. The shape and size of the scrap tire problem and some potential solutions. In: Conference on Tire Technology Clemson Proceedings; 1986; Clemson. Clemson: University Greenville; 1986.

15. Brydon JA. Rubbery materials and their compounds. Nova Iorque: Elsevier Applied Science; 1988.

16. Barlow FW. Rubber compounding: principles, materials, and technics. Nova Iorque: Marcel Dekker; 1993.

17. Panzera TH, Strecker K, Sabariz ALR, Mendonça THS and Bowen CR. Investigation of the incorporation of rubber wastes in polymeric composites using full factorial design. In: Proceedings of the 11th International Conference on Nonconventional Materials and Technologies; 2009; Bath. Bath: University of Bath; 2009.

18. Crawford RJ. Plastics and rubber: engineering design and applications. London: Amer Society of Mechanical; 1985.

19. Sobrinho LL, Calado VMA and Bastian FL. Effects of rubber addition to an epoxy resin and its fiber glass reinforced composite. Polymer Composites. 2012; 33(2):295-305.

20. Minfeng Z, Xudong S, Huiquan X, Genzhong J, Xuewen $\mathrm{J}$, Baoyi $\mathrm{W}$ et al. Investigation of free volume and the interfacial, and toughening behavior for epoxy resin/rubber composites by positron annihilation. Radiation Physics and Chemistry. 2008; 77(3):245-251.

21. Jumaat MZ, Salam MA, Islam MS and Hashim R. Utilization of solid wastes in construction materials. International Journal of the Physical Sciences. 2010; 5(13):1952-1963.

22. Silva TAA, Panzera TH, Brandão LC, Lauro CH and Scarpa F. Preliminary investigations on auxetic structures based on 
recycled rubber. Physica Status Solidi (b). 2012; 249(7):13531358.

23. Sigmund O. Tailoring materials with prescribed elastic properties. Mechanics of Materials. 1995; 20(4):351-68.

24. Matsuoka T, Yamamoto S and Takahara M. Prediction of structures and mechanical properties of composites using a genetic algorithm and finite element method. Journal of Materials Science. 2001; 36(1):27-33.

25. Masters IG and Evans KE. Models for the elastic deformation of honeycombs. Composite Structures. 1996; 35(4):403-22.

26. Javadi AA, Faramarzi A and Farmani R. Design and optimization of microstructure of auxetic materials. Engineering Computations. 2012; 29(3):260-276.

27. Silva AS, Nacif GCL, Panzera TH, Christoforo AL, Batista FB and Mano V. Incorporation of rubber wastes into thermorigid polymeric matrix composites. Matéria (Rio de Janeiro). 2012; 17(4):1158-1165.
28. Scarpa F, Panayiotou P and Tomlinson G. Numerical and experimental uniaxial loading on in-plane auxetic honeycombs. The Journal Strain Analysis for Engineering Design. 2000; 35(5):383-388.

29. Kennedy J and Eberhart R. Particle swarm optimization. In: Proceedings of the IEEE International Conference on Neural Networks; 1995; Piscataway. Piscataway: IEEE; 1995. v. 4. p. 1942-1948.

30. Kennedy J. The particle swarm: social adaptation of knowledge. In: Proceedings of the IEEE International Conference on Evolutionary Computation; 1997; Washington. Washington: IEEE; 1997. p. 303-308.

31. Lee JH, Choi JB and Choi K. Application of homogenization FEM analysis to regular and reentrant honeycomb structures. Journal Material Science. 1996; 31:4105-4110. 